\title{
Changing the dental landscape
}

Peter Ward, Chief Executive BDA

The BDJ Upfront section includes editorials, letters, news, book reviews and interviews. Please direct your correspondence to the News Editor,

Kate Quinlan at BDJNews@nature.com. Press releases or articles may be edited, and should include a colour photograph if possible.

$\mathrm{T}$ he British Dental Association (BDA) announced in September that we have decided to enter a collaborative agreement with the Dentistry Show to create a whole new Event - the British Dental Conference and Dentistry Show. This development forms part of a wider platform of changes that are based on our ambition to offer our members a wider range of ways to gain value and to interact with us. In this respect we realise that 'value' means different things to different people. As within all professional communities, there exists a variety of expectations.

When we talked to members (and people who would be members) you told us that you value high quality $\mathrm{CPD}$ and opportunities to gather with colleagues. You told us that you wanted a mix of things, some large centralised gatherings and some closer to hand. You told us that you wanted a better developed range of activities at branch and section level. And vitally, you told us that you are busy people who want to be able to access your BDA membership in a range of formats - and most significantly electronically.

The BDA's Conference has grown to be a big event with lots going on and with a wealth of high profile and respected speakers. We have been very proud of it as the event where members can get education, industry updates and importantly meet their friends and peers. For many members it is the centrepiece of the year and we were keen to preserve and grow that event and to make it even more pivotal in the dental calendar. The creation of the British Dental Conference and Dentistry Show allows us to do that. Working with CloserStill Media, we have developed an offering that will ensure that the BDA is centre stage, with our own designated theatre and a VIP lounge for Expert and Extra BDA Members. Members will have priority access to our usual highest calibre speakers within the BDA theatre. But we can offer even more than that. Within the wider event, there will be a range of other themed theatres offering a range of tailored content. We will be working with CloserStill to help to refine and modify the programme and to make sure that all attendees can get a really first rate CPD experience. This is a long-term relationship and both the BDA and CloserStill are committed to ensuring that conference attendees see year-on-year improvements and we will be working hard to achieve that.
This will be aligned with our existing emphasis on providing easily retained and recorded CPD files for members and non-members alike and for the wider dental team. We will be looking to the wider dental community to work on development of joint offerings and events to make sure the BDA is wherever you want it to be.

Under our prior arrangements, we were aware that as popular as it was, for some, the BDA Conference just didn't fit with their

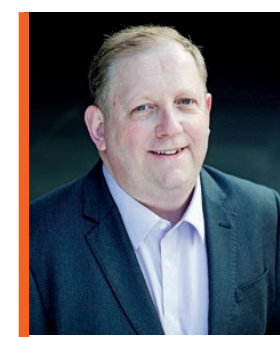

\section{'We are excited by the opportunity to pool our} resources with the

\section{Dentistry Show and to go on to bigger and better national events...'}

For colleagues in the dental industry, we are hoping that this development will also provide advantages. Previously, there were three big dental events in the calendar. That caused exhibitors both some confusion and the need to spread tight marketing budgets thinly. The reduction to two events - The British Dental Conference and Dentistry Show in May and BDIA Dental Showcase in October makes things more straightforward and allows exhibitors to have two clear opportunities to make contact with the profession.

The impact for the BDA is even wider though. By consolidating the delivery of conference, we will now have the opportunity to concentrate on the other things you have asked us for. We will be turning our attention to specific one-off events and to greater activity in our branch and section networks. lifestyles and their work patterns. In spite of offering free tickets to Extra and Expert Members only a small proportion of those eligible availed themselves of them. As we move forward we will be able to offer a wider mix of offerings to all members and specifically of high quality events as part of the Expert and Extra packages. You have told us that you wanted more choice and that is what we are trying to deliver.

So, our announcement in September was a big one for us. We are excited by the opportunity to pool our resources with the Dentistry Show and to go on to bigger and better national events. But this also marked the beginning of a more targeted BDA and one that we will believe will offer even more value to even more members.

Together, we are stronger. DOI: 10.1038/sj.bdj.2017.842 